\title{
Women, forced caesareans and antenatal responsibilities
}

\author{
Heather Draper University of Birmingham, Birmingham
}

\begin{abstract}
In the UK in October 1992, Mrs $S$ was forced to have a caesarean section despite her objections to such a procedure on religious grounds. The case once again called into question the obligations of women to the unborn, and also whether one person can be forced to undergo a medical procedure for the benefit of someone else. Re S, like the case of Angela Carder, is often discussed in terms of the conflict between maternal and fetal rights. This paper looks instead at our obligations to save life in general - whether or not we are pregnant - and at the obligations of mothers to their childrenwhether they are born or unborm. Drawing on fudith Farvis Thomson's distinction, it argues that minimal decency informs the duties which are owed to strangers, but that parents can be expected to behave as Good Samaritans towards their children. Finally, it is argued that even if mothers are ethically obliged to consent to caesarean sections which will save the lives of their babies, this does not necessarily mean that others are at liberty, or even obliged, to proceed with such operations without their consent.
\end{abstract}

In the UK in October 1992, Mrs S was forced to have a caesarean section despite her objections to such a procedure on religious grounds. 'The case once again called into question the obligations of women to the unborn, but also whether one person can be forced to undergo a medical procedure for the benefit of someone else. This paper rejects analysis of the conflict between maternal and fetal rights as a model for resolving cases such as $\operatorname{Re} S$ through a closer examination of the rather more infamous US case of Angela Carder.

\section{The case of Angela Carder}

In 1987, Angela Carder was diagnosed as having terminal cancer of the lung. She was twenty-five weeks pregnant and it was expected that she would only survive for a week. Angela had lived under the

\section{Key words}

Ethics; forced caesareans; overriding consent. shadow of cancer since she was thirteen, but had thought herself to be in remission when she planned her pregnancy. Whilst insisting that her own comfort must be the primary consideration, she agreed in principle to consent to any treatment which might enhance the survival prospects for her baby. Her husband, parents and physician were in full agreement with these wishes. Almost a week later, she refused her consent for a caesarean section and the hospital decided to seek legal advice. Angela believed that it was unlikely that such an immature fetus would survive, and that if it did, it would be likely to suffer multiple disabilities. Emmett Sullivan, the judge appointed to the case, decidede that the pivotal issue was the fetus's chances of survival and what was in its best interests granted its mother's terminal condition. He ordered the caesarean section to take place. Angela still refused to consent so Sullivan again listened to both counsels but reaffirmed his original decision. Less than one hour later and with the section planned to occur within fifteen minutes, Angela's counsel argued that the operation would foreshorten her life and was not therefore in her best interests. Against this it was argued that she had no interests as she was dying. Sullivan cut across the ensuing argument by asking who had the best chances of surviving, the mother or the child. The answer was that the baby did and so he again ordered the operation to take place. The non-viable fetus died two hours after the caesarean was performed. Angela died two days later. At no point in the proceedings did Sullivan speak to Angela personally. In 1990, two appeal hearings later, the District of Columbia Court of Appeal reversed Sullivan's decision, not for the benefit of Angela, but to avoid setting a precedent for future cases.

This was, undoubtedly, a horrific case. Sullivan's attitude to Angela and his ultimate judgment have been roundly condemned and the decision on appeal applauded. At first glance, the case has little in common with that of Re S: not only was the fetus very immature but the management of immature fetuses in special care has improved enormously in the intervening years; moreover there were more serious implications for Angela's health than were 
apparent for Mrs S. Indeed, using the Carder case as a focus for a discussion which will largely condemn the imposition of caesarean sections, could be seen as setting up a "straw man" for easy demolition. However, closer examination of this case reveals that it has more in common with the trickier cases - those involving viable fetuses and where the woman concerned is objecting on religious grounds or from fear of surgery - than might first appear. Carder was decided by defining the problem as one of a conflict between maternal and fetal rights. The question of whether a woman should be forced to have a caesarean section is still, by and large, discussed within the context of this conflict. I will argue that paying closer attention to what Angela actually said highlights other important, and common, principles which must also be given weight in cases where pregnant women are apparently threatening the interests of the unborn.

\section{Maternal v fetal rights}

The usual way of determining the ethics of enforcing caesareans is to analyse the conflict between maternal rights and fetal rights. Because the fetus is contained within his or her mother's body, nothing can be done to him or her without the mother's consent. If the refused operation to save his life is to take place, it has to be shown that his right to life is greater than her rights of control over her body.

The same set of issues is debated in the case of abortion, but in caesarean sections they are even more complex. Whilst the potential harm to the woman is greater than in abortion, the status of the fetus is even more difficult to determine. Typically, he will be viable, mature and nearer to birth, the point at which he gains a legal right to life by virtue of his independence from a woman's body. Accordingly, some people who might normally argue in favour of a woman's right to choose what happens to her body in relation to abortion, find themselves reluctant to endorse a woman's right to refuse a caesarean section which would save the life of a viable and mature fetus. But forcing a pregnant woman to act for the benefit of an unborn child could be the start of a slippery slope to other invasive fetal therapies and to the prohibition of lifestyles thought to harm the fetus in utero. Ultimately, it may even lead to a prohibition on abortion. Arguments against forced caesareans tend to rely on the premise that as a pre-person, the fetus even at term - has a lower moral status than his mother. Unfortunately, this line of argument may place us on a different slippery slope, this time towards infanticide - a consequence as unattractive as that of abortion being prohibited.

Arguments in favour of imposing caesarean sections tend to draw on the kinds of arguments put forward by Judith Jarvis Thomson, ${ }^{2}$ based upon what it is minimally decent to do when a life depends on one's actions. Thomson side-steps the status issue by arguing that even if the fetus is granted the right to life (which she defines as the right not to be killed unjustly), women are not necessarily obliged to continue with a pregnancy when the cost of so doing is more than that which would, in parallel circumstances, be required of others to save a life. She draws a distinction between being a Good Samaritan (ie doing that which is supererogatory) and being minimally decent. Consenting to a fetus's dependence on one's body partly determines minimal decency in this context (and is vital in any understanding of what a fetus may be said to have a right to), but even lack of consent is not decisive in circumstances where the costs to the woman are relatively small in terms of the gains for the fetus. She argues that policies concerned with abortion should reflect minimal decency and should not require women to be Good Samaritans. It is not difficult to see how these arguments can be brought to bear in a defence of enforcing caesarean sections Whilst the cost to a woman of saving a life by having a caesarean section is not insignificant, it is not sufficiently high to justify a refusal of consent because the gain to the fetus - the saving of his life is so great.

A further argument is that having decided to take the pregnancy to term, a woman has an additionah responsibility to the fetus to agree to a caesarearo section since a mechanical delivery is a well-known possible outcome of confinement. Opting to् continue with a pregnancy is, effectively, consenting to all that is involved in carrying a child to term and being delivered of him. ${ }^{3}$

The rest of this paper will look in greater detail at these two arguments. The first employs a notion of minimal decency in the context of saving life. Such an argument should be applicable to everyone, not just to pregnant women. The second suggests that women who have chosen to go to term have a special set of responsibilities, special in the sense that they are not shared by everyone. But, as we will see, this argument is only valid if it is seen as part of parental responsibility, in which case these special obligations - to act as Good Samaritan - cannot be limited to pregnant mothers, but extend to non-pregnant parents, mothers and fathers alike.

\section{Responsible antenatal parenting}

Focusing solely on the conflict between maternal and fetal rights may distort the issues surrounding a woman's refusal of a caesarean section and may obscure other ethical considerations necessary for an ethical resolution. It does not, for instance, require any great understanding of the reasoning behind her reluctance to consent. The conflict debate proceeds as if the woman is simply saying: "This is my body, I can do with it as I please. If it does not please me to have this caesarean, you can't make me". That this is a completely false view is highlighted by the Carder 
case. Angela was saying two things. First, that she would not agree to a procedure that could leave her baby multiply disabled albeit alive (possibly). Second, because her baby was so immature and unlikely to survive, her care and comfort as she died should be the priority. Before the possibility of a caesarean was introduced, she had agreed that provided her care and comfort came first, she would consent to any treatment which might prolong her life enough to give her baby a better chance of survival. ${ }^{4}$

Both statements are reasonable expressions of parental responsibility and both are completely obscured by the conflict model. The first draws on our understanding of parental consent on behalf of children, the second informs discussion about the limits of parental obligations to save the life of a child. Both warrant greater attention.

\section{Proxy consent}

When a child is very ill, her parent(s) expect(s) to be consulted about the treatment which the child will receive and to be kept informed about her progress and prognosis. This expectation flows from the accepted ethical practice that when someone is unable to consent for herself (and has never been in a position to make an advance directive), consent should be given on her behalf by the person who can best represent her interests. Where children are involved, proxy consent is generally entrusted to parents on the assumption that they will always have the best interests of their children at heart. This trust in parents is, more often than not, well founded, but because the notion of the patient's best interests justifies both proxy consent and the choice of proxy, there is no absolute right of parental consent and parents cannot do anything they want with or to their children. The House of Lords judgment in the case of Gillick reinforced this understanding by asserting that parental privilege rather than parental rights was the correct formulation of parental responsibilities to give proxy consent for a child. ${ }^{4}$ Parental consent must, therefore, reflect the normal understanding of a child's best interests.

Occasionally, parents want something which, by fairly conventional standards, will not benefit their child, for example, they may refuse a blood transfusion on religious grounds. Here there is a tension between beliefs about the means to eternal life on the one hand, and the more conventional view that adverse consequences of religious beliefs should not be imposed on those unable to accept such beliefs voluntarily, on the other. Less rare, unfortunately, are cases of child abuse. Here it is obvious that parents quite simply want something which will not only fail to benefit their children but will harm them, and harm them severely. Accordingly, society can justifiably intervene to prevent such a harm (re)occurring. This analysis - that society should intervene when parents jeopardise wellbeing - does not work in cases where harm is minimal or unlikely. In these cases, parental wishes are usually respected, for instance, keeping children away from school for the odd day, out of respect for a religious feast day. In health care, a comparable case may be one where no one can say for certain what the best therapy will be: here too, parents may be given the final say. For example, the decision to choose palliation and certain death for a terminally ill child rather than a painful experimental therapy which holds only a small or remote hope of cure or extended life.

One aspect of Angela's case which was neglected was her views as a parent. Part of her justification for refusing to consent was her judgment about what was a good therapy for her child in one of these tricky borderline cases where best interests do not readily translate into choosing the pro-life option. The recurrent complaint that pregnant women are only viewed as the vessel in which the fetus is housed is apposite here. Viewing her case as a test of maternal or fetal rights distorts the picture. Angela was more than just a pregnant vessel refusing a caesarean section in order to ensure her own peaceful death. She was also someone who had willingly chosen to become a mother and who recognised that for such women, parental responsibilities begin before birth. ${ }^{6} \mathrm{Her}$ refusal of consent to a therapy which was proposed ip the interests of her child, and which she believed rap contrary to those interests, can be justified, withou recourse to any discussion of whether it reflected at right over her body or not. One justification might be that morally responsible motherhood requires women to consider the best interests of the unborn children which they have chosen to mother. Another is that having decided that the child is going to be born, the woman bearing him has an obligation not to injure him irrespective of whether or not she intends to mother him personally. This obligation is rooted in the general responsibility to avoid avoidable harms. Angela's second reason for refusing to consent was related to her first; the chances of the child's surviving were slight. Although Sullivan emphasised that the fetus's chances of surviving were greater than Angela's, he did not apparently understand that survival in either case was unlikely. A more appropriate resolution may have been reached by asking how much one person can reasonably be expected to sacrifice in order to save the life of another, especially when the chances of actually succeeding are remote.

Angela was being asked to sacrifice a peaceful death and possibly also a little of what was left of her life. This was a great deal to ask of anyone to save the life of another - a little like asking a terminally ill and dying patient to give up his bed for another patient whose survival prospects are only marginally better. To give it would be extremely generous, rather than obligatory. Angela was not, however, just someone; she was also the baby's mother. Was it also, therefore, too much to ask of a parent, if the sacrifice would 
save the life of his child? The answer to this question is probably that it would not be too much to expect, provided it would save the life - which in Angela's case was unlikely. Again, it would have been extremely generous of Angela to agree but it was not required. If, however, the situation had been different and the baby's chances of survival greater, then it is arguable that Angela would have been ethically obliged to consent. Indeed, everything she said suggests that this is something she would willingly have done.

It has now been shown that there were some very good reasons for Angela not to consent to the operation, which are obscured if the situation is reduced to one of maternal versus fetal rights. What is not being argued here is that the issue of control over one's own body has no part to play in such discussions; clearly the fact that the fetus is within his mother is part of the complexity of the situation and cannot be ignored. What is being argued is that looking at the picture as though competing rights were the central or only aspect of the circumstances obscures or distorts other ethical obligations in play.

\section{Duties of strangers and duties of parents: minimal decency and the Good Samaritan}

It has been argued that a pregnant woman may be ethically obliged to consent to a caesarean section which would save the life of her unborn child, even though this is a type of sacrifice which may not be required of someone to save the life of a complete stranger. There are, however, two groups of women who must be exempt from this obligation: those who have either not willingly become pregnant or who have not willingly continued with their pregnancy; and those who have willingly continued their pregnancy, but have done so only to preserve the life of a baby which they have no intention of parenting. For the purposes of this paper, we may grant that such women have the status of strangers rather than parents in relation to the unborn child.

What might be expected of a stranger if this was necessary to save a life? A relevant case here is that of McFall v Shimp. ${ }^{7}$ McFall was dying and Shimp (his cousin) was the only person known to have compatible bone marrow, a transplant of which would save McFall's life. Shimp refused to donate, so McFall attempted to force Shimp to comply on the grounds that his life depended upon the transplantation. A court decided that Shimp could not be compelled to donate and McFall died. This outcome seems inconsistent with judgments both in the USA and the UK imposing caesarean sections on women to save the life of a fetus. It was extremely ungenerous of Shimp to refuse his help, but then many of us are equally guilty of refusing to help strangers under comparatively less costly circumstances, for example by making regular blood donations. Siding with
Shimp rather than McFall enables us to continue to avoid making such personal sacrifices for the common good. Even if the standard of minimal decency is set quite high with regard to small personal physical sacrifice to save a life, it is all too easy to argue that the individual's obligation is less because the help of some other person would suffice. Clearly, this is not so with enforced caesareans. If we are, however, inclined to think that Shimp should have donated the marrow, then we should also be inclined to think that a pregnant "stranger" should be prepared to have a caesarean for the sake of the fetus. Whether we take consent to be an imperative, or only supererogatory, will depend upon how high we are prepared to set the standard of minimal decency with respect to saving the life of another.

But what of parental obligations? On the argument so far, if Shimp had been the parent of McFall, his refusal would have been all the more unethical. Taking on a parental role does involve an obligation to make sacrifices for one's children that one would not be obliged to make for strangers. This obligation falls equally on both parents, though, under some circumstances it might fall on one rather than the other. In the modified case of Shimp, for instance, it is not unjust (though it may be bad luck) that it is $\mathrm{Mr}$ Shimp whose bone marrow is compatible with child McFall's, rather than Ms McFall's (the child's mother). Mr Shimp cannot escape his parental obligation by arguing that it is unfair that he rather than she has the operation, because only his bone marrow is compatible. Likewise, a general argument against caesarean sections cannot be made on the grounds that it is only women who face these decisions and that this places an unequal burden upon them. The burden is only unequal if men would not be expected to do the same in parallel cases.

\section{Enforcing obligations}

No claims have yet been made about whether caesareans should be forced upon either parents or strangers. Although the question of force has to be resolved, it need not be resolved by returning to the conflict between maternal and fetal rights. It may also be discussed in the wider context of parental or stranger's duties.

The use of the terms "parent" and "parental" rather than "mother" and "maternal" when referring to such obligations has been deliberate. This is where the emphasis should lie when attempting to resolve the issue of enforcing ethical responsibilities. The maternal versus fetal rights analysis suggests that the whole problem can be solved either by women regaining control over their bodies and by everyone accepting that the fetus has no rights until he is born or by women accepting that the right to life takes precedence over control of the body. The complexity of the problem is thereby obscured, most 
especially, the general responsibilities of us all in relation to the unborn.

Resolving the conflict in favour of the fetus means that numerous other responsibilities are also overlooked. The threat which women pose to fetuses by refusing to have caesarean sections is dwarfed by the threat which social inequalities and environmental factors such as pollution pose. If a fetus does have a right to be protected from harm, then this should extend to all harm and not just that posed by his mother. Similarly, resolving the conflict between the mother's rights and the fetus's rights in favour of the mother suggests that keeping a fetus from harm is a matter of choice, whereas preventing many of the things which cause fetuses harm may be beyond the means of ordinary women.

\section{Smoking}

Accordingly, it is one thing to show what a woman ought do in relation to her unborn child and quite another to say that this obligation ought to be enforced. There are many ways to keep the fetus from harm, it is difficult to see why the responsibility for these is the sole burden of pregnant women. This point becomes clearer when a different example is used, for instance smoking during pregnancy.

It has been argued that if women are forced to have caesareans for the sake of their fetuses, it is not unreasonable that they should also be forced to stop smoking whilst pregnant. Let us put aside for the moment the issue of force, and rephrase the claim: if a woman is obliged to protect her fetus from harm by having a caesarean, then it is not unreasonable to suppose that she might also be obliged to stop smoking to the same end. The argument that mothers have greater responsibilities than women in general merely strengthens the argument in favour of stopping. However, this is just part of the picture and concentrates on women to the exclusion of other parties with similar responsibilities. First, it assumes that smoking does pose a significant threat to the life of the fetus. Whilst all agree that the fetus is compromised by smoking, the extent and relative severity of the harm is far from clear. In terms of poor perinatal outcome the effects of smoking are far less severe than those of general and grim deprivation and poverty. Obviously, the harm is greater than that of not smoking, but there are other things which harm fetuses more significantly. Surely, these harms to life and health must also be avoided if there is an obligation to protect the fetus.

Second, the use of the term "fetus", rather than "baby", obscures another related harm. The damage inflicted after birth by passive smoking may be greater than that of the secondary effects of smoking whilst in utero. If there is an obligation on women not to smoke whilst pregnant, there is a corresponding obligation on parents generally not to smoke once their baby is born. Indeed, there is an obligation upon society to ensure that children are not the nonvoluntary subjects of any harm from passive smoking in public places. Restricting the analysis to a conflict between maternal and fetal rights obscures this wider responsibility and keeps women in the unjust and traditional position of feeling, and being held, solely responsible for the care or neglect of care of children. This seems to be to the detriment of both groups concerned, the women and their children.

It is a wider analysis which illustrates why it is unfair to enforce caesarean sections. It is not unfair because mothers are not obliged to consent (under most circumstances) but rather because it is simply inconsistent with other similar obligations which are generally not imposed and enforced upon parents and others in relation to children. It is unjust for women to have surgery forced upon them because society generally is so biased in its imposition of obligations to children. This is not to say that it is wrong per se to impose a caesarean section upon a women if this is necessary to save a baby's life. Granted an equal, more caring and socially oriented society, where the obligations of parenting were shared, it would be difficult to argue against the enforcement of obligations, particularly parental obligations, because good care of children should be mandatory.

However, for such an argument to be compelling it would also have to be shown that such surgery was indeed necessary and that it was the only means be which the life could be saved. This places an obliga tion upon the health care professionals to act responsibly towards both women and fetuses. Caesarean sections have been performed for the convenience of obstetricians, as the consequence of incompetent diagnosis, and as the result of a total break-down in communication between carers and the pregnant woman. A mother can only be obliged to consent to an operation if this is necessary to save the life of her baby. Not surprisingly, many women doubt that caesareans are given only in such circumstances. A shift away from the medicalisation of pregnancy and childbirth is likely in any case to reduce the number of occasions under which caesarean sections might be deemed necessary, and this will inevitably reduce the number of occasions when a woman might object to one being performed.

Also, before any enforcing is done, it is necessary to explore fully the reasons why some women refuse to have caesarean sections performed. A lack of confidence in obstetric advice is one reason. There are others, such as the practice of gaining blanket consent to all procedures even before labour has begun. ${ }^{8}$ In $\operatorname{Re} S$, part of the objection to $S$ 's refusal of consent was that it was based on her religious views. We are generally inconsistent in our policies of allowing parents to impose the consequences of their religious beliefs upon children. Children can be forced by their parents to attend Sunday school or other religious education outside school hours. Certain Christian groups are permitted to found and 
send their children to denominational schools, Muslim parents are not. We allow Jewish parents to circumcise male babies, but do not permit Jehovah's Witnesses to refuse blood transfusions for their children. If pregnant women are unsure about which therapies it is unacceptable to refuse on religious grounds, we should not be surprised. But if such confusion exists, we cannot also argue that women who continue with their pregnancies understand what they are letting themselves in for by so doing.

\section{Conclusions}

If it is minimally decent to undergo some pain and suffering in order to save a life - ie if one thinks that Shimp was wrong not to donate his bone marrow to McFall - then women generally should consent to caesarean sections which will save the life of a baby. If mothers have greater obligations to protect the wellbeing of their children than non-parents have, then all mothers should consent to caesarean sections that will save the lives of their unborn children. But it has yet to be shown that either women generally, or mothers in particular, should be compelled to fulfil their obligations to the unborn. The argument against enforcing the obligation is one based on the injustice of pregnant women being forced to make sacrifices not required of the nonpregnant. But one big objection to this argument is that if women and others declined to act morally until a more equal society were achieved, moral anarchy would ensue. Indeed, such an argument would only perpetuate other injustices. ${ }^{9}$ One would not, for instance, want to free consumers in general from the obligation to pay for goods, just because men engaging the services of prostitutes are under no legal obligation to pay for services rendered. ${ }^{10}$

One interim solution might be both formally to recognise what women's (or more particularly, mothers') obligations to consent are and not to compel them to consent. This might be achieved by holding women (or mothers) responsible for the decisions which they make through an inquiry into the circumstances leading to the baby's death - if indeed this is the outcome. It is a moot point whether such an inquiry should have the power to recommend penalties for damaging behaviour, much as judgments involving child abuse do. There is an important "however" which accompanies this proposal: all extenuating circumstances must be taken into account. It is highly unlikely that women refuse caesarean sections to make a statement about ownership, at whatever cost, of their own bodies (something some anti-feminists would have us believe). For the most part such refusals result from other factors, such as a sincere belief that the best interests of the child will be served or from some distrust of advice received. This can be illustrated by revisiting cases where a refusal of consent for a caesarean section was overruled. A significant and little publicised factor in the $\operatorname{Re} S$ case was that this was the second labour Mrs $S$ had experienced. During her first labour a caesarean was also recommended and refused, but in this case the baby was eventually delivered vaginally. Is it so surprising, therefore, that on this second occasion Mrs S was not prepared to re-consider? It is not unlikely that investigations of deaths which result from a refusal to consent to caesarean sections will reveal that others have to take their share of the responsibility for the refusal of consent. In another case a woman refused her consent - or so her notes record - on the grounds of "an irrational fear of surgery" (is such a fear so irrational?), where she was also described as "angry, obese and uncooperative" indicating that there may already have been a significant breakdown in communication between the woman and those caring for her. She was compelled to have a caesarean and, apparently against the odds due to the time it took to gain the order, the baby was born fit and well. Her obstetrician is reported to have commented that her experience "merely underscores the limitations of continuous fetal heart monitoring"." There is widespread concern not only about the numbers of caesarean sections which are being performed but also about regional variations in these numbers. It is not surprising that in the light of this concern, some women might be reluctant to consent. If a woman does reluctantly consent to a caesarean section, there is no way of discovering whether it was actually necessary. Who, in any case, is likely to complain or be taken seriously if the baby is born safe and well? Since a woman's decision is totally dependent on the competence of her adviser, there is an obligation on those who advise to be sure about the advice they give.

If mothers (and other women) are obliged to consent, then there must be a mechanism for dealing with refusal to consent. The knowledge of a subsequent inquiry may incline (in the Kantian sense) mothers to do what they ought to, but the argument against forced caesarean sections remains intact. The argument against force is further complicated by the fact that until the point of no return, until a woman has actually decided something which has caused the death of the fetus, the potential for a change of heart remains. Compelling someone after the point of no return is a futile exercise. Justice dictates, therefore, that women should be permitted to make their own decisions provided that they are also prepared to face the consequences. What should never be overlooked is the fact that the same arguments which are used to substantiate the claim that women have the obligation to consent also oblige many others to take better care of children's health. My fear is that because women in labour are literally a captive audience, their actions will continue to take attention away from these wider obligations. 
Heather Draper, PhD, is Lecturer in Biomedical Ethics in the Department of Biomedical Ethics, the Medical School, the University of Birmingham, Edgbaston, Birmingham.

\section{References and notes}

1 Re S Family Division 12th October 1992.

2 Thomson J. In defence of abortion. In Singer P, ed. Applied ethics Oxford: Oxford University Press, 1986.

3 Obligation regarding pregnancy and confinement arise from the choice to continue with the pregnancy. This obligation would be weakened if the woman had been free neither to use contraceptives nor to have a termination of pregnancy, a point stressed by Kluge EH. When court imposed caesarean section operations are justified fournal of Medical Ethics 1988; 14: 206-211.

4 Though after only twenty-five weeks' gestation (compromised by her own illness) the absence of steroids to mature the baby's lungs, and granted the technology available in 1987, there was very little that could actually have been done.
5 Gillick v West Norfolk and Wisbech AHA [1985] 3 All E R.

6 It may be argued that parental responsibility can begin before conception. For instance, since folic acid reduces the incidence of neuraltube defects in babies, women should, as recommended, increase their intake of folic acid for three months prior to attempting conception. Similar arguments about prenatal parental responsibilities have been made about couples who may pass on genetic disorders to their offspring.

7 Beauchamp TL, Childress JF. Principles of biomedical ethics Oxford: Oxford University Press, 1983: 315-7.

8 Ladd R. Women in labor: some issues about informed consent. In Holmes H, Purdy LM, eds. Feminist perspectives in medical ethics. Bloomingtom: Indiana University Press, 1992: 216-223.

9 My thanks to Margrit Shildrick for bringing this to my attention and discussing possible solutions.

10 My thanks to Christopher Coope for this analogy.

11 Bowes WA, Selfested B. Fetal versus maternal rights: medical and legal perspectives American foumal of Obstetrics and Gynaecology 1981; 58: 209-214.

\section{News and notes}

\section{New courses}

The Centre for Philosophy and Health Care at the University of Wales Swansea is offering new courses an MA and a Diploma in Medical Humanities (PGEA accredited) - on either a part-time or a full-time basis in 1997. The courses are designed to supplement the limitations of an exclusively scientific and reductionist basis for the teaching of medicine, by bringing candidates to an appreciation of a range of perspecitves and methods of critical reflection within the humanities.
Five key areas are explored: (i) models of mankind and medicine; (ii) sociology and anthropology of medicine and health care; (iii) social history and politics of medicine and health care; (iv) medicine, health care, literature and the arts, and (v) medicine, health care and religion.

For details please write to: Admissions Tutor, Centre for Philosophy and Health Care, University of Wales, Swansea, Singleton Park, Swansea SA2 8PP.

\section{News and notes}

\section{The Ethics of Research on Humans}

The Centre of Medical Law and Ethics of King's College, London is running courses on the Ethics of Research on Humans at King's College, the Strand, London from the 17-19 December 1996, the 23-25 April 1997 and the 1-3 July 1997.
For further information please contact: Continuing Education Unit, King's College, London, Cornwall House, Waterloo Road, London SE1 8WA. Tel: 0171872 3056/3055; fax: 0171-872 3070. 